\title{
The (Perceived) Meaning of Spontaneous Thoughts
}

\section{Citation}

Morewedge, Carey K., Colleen Giblin, and Michael I. Norton. "The (Perceived) Meaning of

Spontaneous Thoughts." Journal of Experimental Psychology: General 143, no. 4 (August 2014): 1742-1754.

\section{Published Version}

http://dx.doi.org/10.1037/a0036775

\section{Permanent link}

http://nrs.harvard.edu/urn-3:HUL.InstRepos:14010994

\section{Terms of Use}

This article was downloaded from Harvard University's DASH repository, and is made available under the terms and conditions applicable to Open Access Policy Articles, as set forth at http:// nrs.harvard.edu/urn-3:HUL.InstRepos:dash.current.terms-of-use\#OAP

\section{Share Your Story}

The Harvard community has made this article openly available.

Please share how this access benefits you. Submit a story.

Accessibility 
RUNNING HEAD: The (Perceived) Meaning of Spontaneous Thoughts

The (Perceived) Meaning of Spontaneous Thoughts

Carey K. Morewedge and Colleen E. Giblin

Carnegie Mellon University

Michael I. Norton

Harvard Business School

Word Count: 8,476

Keywords: Spontaneous Thoughts, Self-Insight, Meaning, Attribution, Judgment and

Decision Making

Corresponding Author:

Carey K. Morewedge

5000 Forbes Ave

237 Posner Hall

Pittsburgh, PA 15213

412-268-6079

morewedge@cmu.edu 
The (Perceived) Meaning of Spontaneous Thoughts - 2

\begin{abstract}
Spontaneous thoughts, the output of a broad category of uncontrolled and inaccessible higher-order mental processes, arise frequently in everyday life. The seeming randomness by which spontaneous thoughts arise might give people good reason to dismiss them as meaningless. We suggest that it is precisely the lack of control over and access to the processes by which they arise that leads people to perceive spontaneous thoughts to reveal meaningful self-insight. Consequently, spontaneous thoughts potently influence judgment. A series of experiments provides evidence supporting two hypotheses. First, we hypothesize that the more a thought is perceived to be spontaneous, the more it is perceived to provide meaningful self-insight. Participants perceived more spontaneous kinds of thought to reveal greater self-insight than more controlled kinds of thought in Study 1 (e.g., intuition versus deliberation), and perceived thoughts with the same content and target to reveal greater self-insight when spontaneously than deliberately generated in Studies 2 and 3 (i.e., childhood memories and impressions formed, respectively). Second, we hypothesize that greater self-insight attributed to thoughts that are (perceived to be) spontaneous leads those thoughts to more potently influence judgment. Participants felt more sexually attracted to an attractive person whom they thought of spontaneously than deliberately in Study 4, and reported their commitment to a current romantic relationship would be more affected by the spontaneous than deliberate recollection of a good or bad experience with their partner in Study 5.
\end{abstract}


Much human thought arises unbidden, spontaneously intruding upon consciousness. The thought and name of a former lover might come to mind during dinner with one's spouse. Or worse, it may be blurted out during an intimate moment. Because no trace of the past lover is present, the thought lacks an apparent cause. In the latter case it almost certainly occurs without intent, given its potential consequences. The seeming randomness of such thoughts might provide reason to dismiss them as the wanderings of a restless mind. We propose that it is precisely the lack of control over and access to the process by which spontaneous thoughts come to mind that leads them to be perceived to reveal special self-insight. Drawing on previous theory and research, we propose that the greater self-insight they are attributed leads spontaneous thoughts to exert a greater impact on attitudes and behavior than similar deliberate thoughts.

Compare a wife's thought of a former lover while perusing her yearbook to that same thought during an intimate moment with her husband. In the former case, the reason for the production of that thought is clear ("I thought of him because I looked at his picture while reminiscing about the past”). In the latter case, she lacks both control over the thought and access to its origin. We suggest that its apparent spontaneity should lead her to attribute it special meaning ("Why would I think of him in this moment unless it is important?”), and it should consequently exert a greater influence on her judgment (“I must still have feelings for him”). In this paper, we report a series of five studies examining how the perceived spontaneity of thought influences the extent to which it is believed to yield meaningful self-insight and influences judgment. 
The (Perceived) Meaning of Spontaneous Thoughts - 4

\section{THE (PERCEIVED) MEANING OF SPONTANEOUS THOUGHT}

People believe their thoughts to be the primary driver of their behaviors and external features of their environment to be secondary, going so far as to create reasons for why their thoughts caused their behavior even when that behavior was induced by the situation (e.g., Bar-Anan, Wilson, \& Hassin, 2010; Nisbett \& Wilson, 1977; Ross \& Nisbett, 1991; Wilson, 2002). We suggest that people imbue spontaneous thoughts with particular importance. We define spontaneous thoughts as thoughts produced by a broad category of higher-order mental processes that cannot be controlled or accessed by the thinker (Miller, 1962; Nisbett \& Wilson, 1977), as in the example of an unbidden thought of a former lover. Unlike previous investigations aiming to define the necessary conditions for a thought to be considered truly spontaneous (Smallwood \& Schooler, 2006), we examine how lay beliefs about the spontaneity of a particular thought influence the perceived self-insight and importance it is attributed. In other words, we explore the special meaning that ascribed to thoughts that people perceive to be spontaneous, regardless of whether or not those thoughts actually occurred as the result of a spontaneous thought process.

We draw on theorizing and empirical data in three domains to make our prediction that thoughts perceived to be spontaneous are attributed meaningful selfinsight: Previous research documenting (a) the confidence placed in and perceived diagnosticity of one particular type of spontaneous thought-intuition, (b) the importance attributed to spontaneous thoughts elicited by a variety of clinical, cognitive, and social psychological methods, and in (c) the impact of different kinds of self-generated spontaneous thoughts on judgment and behavior. Although research in each of these 
The (Perceived) Meaning of Spontaneous Thoughts - 5

domains may appear at surface to be quite different, we suggest that together they provide converging evidence that supports our theory.

First, people generally believe their thoughts reflect the true state of the world (Gilbert, 1991; Griffin \& Ross, 1991; Pronin, Gilovich, \& Ross, 2004), and exhibit a strong belief in the veracity of their intuitions (Kahneman \& Frederick, 2002;

Morewedge \& Kahneman, 2010). People are reluctant to question their intuition even when reason suggests they should. They are quick to accept intuitive answers that would be proved wrong by a moment of reflection (Frederick, 2005), and erroneously believe it is better to stick with their intuitive answers when subsequent deliberation or considerable external evidence suggests that it is wrong (Kruger, Wirtz, \& Miller, 2005). Gambling decisions, for example, tend to be biased in favor of intuitive outcomes (the favorite team beating the point spread) even when alternative outcomes are as or more probable (the underdog beating the spread; Simmons \& Nelson, 2006). Intuitions are insufficiently discounted even when people are explicitly aware that their intuitions are wrong, as illustrated by self-generated anchoring effects (Epley \& Gilovich, 2001; 2006; Simmons, LeBoeuf, \& Nelson, 2010).

Second, methods designed to elicit spontaneous thoughts such as hypnosis, meditation, and projective tests, which encourage people to observe and interpret even their most private thoughts, often result in the production of thoughts that are perceived to provide special self-insight or meaning (Cramer, 1991; Jacoby \& Kelley, 1992; Murray, 1951; Poole, Lindsay, Memon, \& Bull, 1995; Wegner \& Smart, 1997; Westen, 1991; c.f., Holmes, 1968). Despite serious questions regarding the accuracy of memories recovered during hypnosis (Loftus, 1993; Loftus, Garry, Brown, \& Rader, 1994; 
Schooler, Bendiksen, \& Ambadar, 1997), for instance, laypeople place considerable weight on the thoughts and memories elicited by these techniques (Green \& Lynn, 2005). Moreover, patients believe recovered memories offer self-insight only to the extent that those memories appear to have been spontaneously recovered during therapy rather than suggested by their support group or therapist (Bowers \& Farvolden, 1996). Note that in all cases, the recovery (or construction) of memories is a process initiated by the patient at the direction of the group or therapist. We suggest that when the patient lacks control over or direct access to the source of that memory, its recovery is perceived to have occurred spontaneously, leading her to believe the memory provides meaningful insight into her past.

Third, research on thought production and retrieval has shown when one generates thoughts that conflict with the thought one intended or that the circumstance suggests—such as Freudian slips, implicit stereotypes, suppressed thoughts, and counterarguments—-those conflicting thoughts are believed to be important. Recollection and production errors such as slips of the tongue are believed to provide access into unconscious processes (Jacoby \& Kelley, 1992; Norman, 1981). Similarly, takers of an Implicit Association Test (Greenwald, McGhee, \& Schwartz, 1998) certainly do not intend to be more facile in associating negative words with Black than White faces. The very fact that these associations appear to occur spontaneously is, in part, what makes them feel so genuine and upsetting (Banaji \& Baskhar, 2000; Frantz, Cuddy, Burnett, Ray, \& Hart, 2004).

The spontaneous intrusion of intentionally suppressed thoughts leads them to be endowed with meaning and influence conscious beliefs, emotions, and behavior (Wegner, 
2009). Suppressed thoughts can elicit stronger emotions and cravings than the same thoughts if deliberately evoked (Erskine \& Georgiou, 2010; Wegner, Shortt, Blake, \& Page, 1990). Smokers who attempted to suppress thoughts of smoking for one week smoked more in a subsequent week than did smokers told to deliberately think about smoking the previous week and smokers given no instructions (Erskine, Georgiou, \& Kvavilashvili, 2010). So potent is the tendency to attribute meaning to intrusive thoughts that chronic failure to dismiss them as meaningless has been linked to obsessivecompulsive and self-injurious behaviors (Magee \& Teachman, 2007; Najmi, Wegner, \& Nock, 2007).

Spontaneously generating countervailing thoughts can similarly impact beliefs and behavior. When people try to recall many corroborating examples of a trait they possess or an experience, such times when they acted assertively or were happy as a child, corroborating examples become hard to produce and they tend to spontaneously recall contradictory examples (e.g., times when they were unassertive or unhappy; Schwarz et al., 1991; Tormala, Falces, Briñol, \& Petty, 2007; Winkielman \& Schwarz, 1991). Rather than label the recollection of these contradictory examples as meaningless or due to the increased accessibility of that topic, people imbue their recollection with importance. When people attempt to generate many examples of their assertiveness or happy childhood, for instance, it leads them to believe they are less assertive or that their childhood was less pleasant than if they attempted to generate a few examples.

\section{WHY MEANING IS ATTRIBUTED TO SPONTANEOUS THOUGHTS}

The research reviewed above suggests that people appear to imbue a broad array of spontaneous thoughts with special meaning and importance. We propose that the 
special status of each of these subordinate members of the larger category is conferred by the perception that spontaneous thoughts are products of uncontrolled mental processes that have no readily identifiable source. We base our prediction on decades of research on priming, intuitive judgment, preference construction, and the interpretation of dreams.

The influence of primes on judgment, behavior, and motivation is determined to a large extent by the degree to which the perceiver lacks access to the cause of the increased accessibility of the primed construct and misattributes it to her natural response to the situation (for a review, see Loersch \& Payne, 2011). High physiological arousal resulting from standing on a wobbly suspension bridge, for example, can be misattributed to the presence of another person and be interpreted as evidence of sexual attraction to that person (Dutton \& Aron, 1974). The influence of that arousal on perceived attraction, however, is moderated by the ambiguity of the source. It is substantially larger when its source is ambiguous (when its connection to the bridge is not recognized) than when its source is unambiguous (when its connection to the bridge is recognized). When the external source of arousal is unambiguous people correct their judgments of attraction, provided that they have sufficient cognitive capacity to make the correction (Foster, Witcher, Campbell, \& Green, 1998). Judgments can even be contrasted away from the primed construct when people are aware of its source (the prime) and its irrelevance (Bless \& Schwarz, 2010).

People generally tend to question their intuitions only when they know their intuitions are blatantly wrong, or believe their thoughts were contaminated by some biasing external influence (Alter et al., 2007; Schwarz \& Clore, 1983; Wegener \& Petty, 1995; Wilson \& Brekke, 1994). People perceive the content of their thoughts to reveal 
more diagnostic information about the self than their behaviors and choices (Andersen, 1984; Andersen \& Ross, 1984). Yet, people similarly perceive their own behavior and choices as reflecting their true preferences to the extent that they see their behavior as chosen without influence versus when the external (situational) influences that led them to that choice are clear (Ariely \& Norton, 2008; Bem, 1972; Bem \& McConnell, 1970; Festinger \& Carlsmith, 1959; Goethals \& Reckman, 1973; Loersch \& Payne, 2011; Ross \& Nisbett, 1991).

Perhaps the best evidence of the process by which meaning is attributed to thoughts is the widely held belief that dreams contain important information about the self and the external world. The belief that thoughts that occur in dreams are more meaningful than similar thoughts that occur while awake has been linked to the notion that thoughts that occur in dreams have no proximate cause. Because people lack control over and access to the process by which their dream content is generated (Dorus, Dorus, \& Rechtschaffen, 1971; Nikles, Brecht, Klinger, \& Bursell, 1998; Wegner, Wenzlaff, \& Kozak, 2004), they lend such credence to their dreams that dreams can influence their attitudes and behavior to a greater extent than similar conscious thoughts (Morewedge \& Norton, 2009).

\section{THE PRESENT RESEARCH}

We propose an organizing framework to explain the special meaning and impact attributed to the broad category of spontaneous thoughts. We suggest that the lack of control over and access to the process by which spontaneous thoughts are produced leads people to believe they provide particularly meaningful self-insight. In turn, the greater 
The (Perceived) Meaning of Spontaneous Thoughts - 10

self-insight spontaneous thoughts are attributed leads them to exert a greater impact on judgment.

Studies 1, 2, and 3 tested our first hypothesis — that the more spontaneous a kind of thought, the more it is believed to provide meaningful self-insight. Participants in Study 1 evaluated the degree to which a wide range of thoughts occur spontaneously or are controlled and rated the extent to which they believe each kind of thought provides meaningful self-insight. We predicted that participants would believe that the more spontaneous a kind of thought, the more self-insight it reveals. Study 2 examined whether people believe the same particular thought provides more or less self-insight when it is generated spontaneously than deliberately. We predicted that participants would attribute greater meaning to a thought occurring as the result of a spontaneous process rather than a deliberate process, regardless of whether that thought was positive or negative. In Study 3, we prompted participants to generate thoughts spontaneously or deliberately and then rate the extent to which those thoughts provided meaningful self-insight. Even when controlling for potential differences in content, we predicted that participants would attribute greater self-insight to spontaneously than deliberately generated thoughts.

Studies 4 and 5 tested our second hypothesis: because more meaningful selfinsight is attributed to thoughts that appear spontaneous than to thoughts that appear deliberate, spontaneous thoughts exert a greater impact on judgment. Participants in Study 4 generated a thought of a love interest spontaneously or deliberately, reported the self-insight that the thought provided, and then reported their attraction toward that love interest. We expected that participants would attribute greater self-insight to the thought of that person if the thought was generated spontaneously, and that the greater meaning 
attributed to the thought would lead it to exert a greater influence on their reported attraction toward that person. Study 5 extended the research by testing whether this greater influence would extend to both positive and negative spontaneous thoughts. We predicted that the spontaneous recollection of a memory of a relationship, whether positive or negative, would have a greater impact on commitment to that relationship than would the deliberate recollection of the same memory.

\section{STUDY 1: CATEGORIES OF THOUGHT}

Our first study was designed to test the hypothesis that people believe that spontaneous kinds of thought reveal more meaningful self-insight than kinds of thought that are more controlled. Participants rated the extent to which 13 categories of thought are spontaneous or controlled, and the extent to which the content of each category of thought provides self-insight. We predicted that the more spontaneous a category of thought, the more it would be believed to reveal meaningful self-insight.

Method

\section{Participants}

One hundred and ninety-one online survey respondents (68 women, $M_{\mathrm{age}}=30.24$, $S D=9.59)$ in a convenience sample received monetary compensation for completing a survey on Amazon Mechanical Turk (AMT) administered in English. (Appendix A describes our sampling procedures for all five studies.)

Procedure

Participants rated the extent to which the content of what they think and say is totally spontaneous or can be controlled while engaged in each of 13 categories of 
The (Perceived) Meaning of Spontaneous Thoughts - 12

thought (i.e., intuition, deliberation, dreaming, Freudian slips, under hypnosis, mind wandering, logical thought, problem solving, random thought, rumination, spontaneous thought, and while under the influence of a truth serum). Each category was rated on a 7point scale with endpoints, Definitely Controlled (1) and Definitely Spontaneous (7). Participants also rated the extent to which the content of each category of thought yields meaningful self-insight or simply reflects the influence of their current environment on a 7-point scale with endpoints, Only reflects my external environment (1) and Only reveals insights about myself (7). Rating order and order of thoughts rated was random, with thoughts nested within ratings.

After reporting demographic information, participants were given an attention filter, "To gauge your attention to rather than your satisfaction with the instructions in this survey, please do not click on any of the values in the scale below,” and were provided with a 5-point scale to ignore with endpoints, Very Unsatisfied (1) and Very Satisfied (5).

\section{Results}

Seventeen participants failed the attention filter and were removed from all subsequent analysis (the direction and significance levels of all tests reported here do not change if these participants are included). No other participants were excluded in this study.

Analysis of within-subjects correlations revealed that the more spontaneous a category of thought, the more participants believed it revealed self-insight, $M_{r}=.21, S D=$ .48 , which was significantly different from an $r$ of $0, t(172)=5.56, p<.001$ (see Figure 
1). There was no effect of rating order on the strength of the relationship between the spontaneity of thought and the insight it was believed to reveal, $t(172)=.50, p=.62$.

To test the nature of the relationship between spontaneity and insight, we next examined their relationship within a curve-fitting regression, which yielded a significant linear fit, $\mathrm{R}^{2}=.69, F(1,11)=24.83, p<.001$. The insight provided by a thought varied as a linear function of its spontaneity, as predicted, $\beta=.83, t(11)=4.98, p<.001$. There was no evidence of a quadratic pattern, $t(11)=.81, p=.44$ (see Figure 1 ). Of the thirteen categories of thought, none was considered an outlier in terms of its spontaneity or the extent to which it was believed to reveal insight into the self, all $Z s \geq-1.48$ and $\leq 1.49$.

Insert Figure 1 About Here

\section{Discussion}

Across a range of categories of thought that vary considerably in their form, participants believed that the more spontaneous a category of thought, the more selfinsight it revealed. This relationship was observed both in the correlational within-subject analyses at the level of participant, and at the item-level analyses at the level of thought. All thirteen categories of thought adhered to this pattern (i.e., were within 2 standard deviations of the mean), offering initial evidence for a close link between the perceived spontaneity of a category of thought and the self-insight it provides.

Of course, the results of Study 1 are correlational, and it is also possible that differences in the typical content of these categories of thought may contribute to the perceived self-insight that they provide. Dreaming, for example, may typically involve 
The (Perceived) Meaning of Spontaneous Thoughts - 14

more sensitive or personal content than planning or problem solving. To control for potential differences in the content of spontaneous and deliberative thoughts and test our theory in an experimental design, participants in Study 2 reported the self-insight that the same positive or negative thought would provide if it were generated spontaneously or deliberately.

\section{STUDY 2: SPECIFIC POSITIVE AND NEGATIVE THOUGHTS}

Participants in Study 2 recalled either a pleasant or unpleasant event from their childhood, and then evaluated the extent to which the recollection of that event would provide meaningful self-insight if it occurred spontaneously or deliberately. We predicted that participants would perceive the memory to reveal more self-insight if it were recalled spontaneously than deliberately, regardless of whether the memory recalled was positive or negative. In other words, we predicted a main effect of the processes by which the memory was recalled, but no interaction with the valence of the memory recalled. (We had no a priori predictions regarding how the valence of memories would influence the self-insight they were attributed.)

\section{Method}

\section{Participants}

Two hundred and one Americans (83 women; $M_{\text {age }}=30.89, S D=10.50$ ) completed a short survey on AMT for monetary compensation (see Appendix A). Procedure

In a between-subjects design, participants were randomly assigned to think of a positive or negative, "event from your childhood now, to consider in the remainder of the 
The (Perceived) Meaning of Spontaneous Thoughts - 15

survey.” All participants then rated the extent to which the recalled event was positive or negative on a 7-point scale with endpoints, (1) Extremely Negative and (7) Extremely Positive. As the critical dependent variable, all participants rated, "To what extent would you consider it to be meaningful (reveal something important about your self) if the event from your childhood came to mind when you tried to remember it [suddenly came to mind spontaneously]?” on two 5-point scales with endpoints, (1) Not at all and (5) Extremely. As a manipulation check, for each method of retrieval participants rated, "If the thought came to mind when you tried to remember it [suddenly came to mind spontaneously], to what extent would you say that thought occurred spontaneously or as a result of a controlled thought process?” on two 7-point scales with endpoints, (1) Definitely Controlled and (7) Definitely Spontaneous. The order of the dependent variable and manipulation check was counterbalanced between participants. Finally, participants reported their age and gender.

Results

\section{Manipulation checks}

Participants instructed to recall a positive event recalled a more positive event ( $M$ $=6.01, S D=1.15)$ than did participants instructed to recall a negative event $(M=2.15$, $S D=1.30), t(199)=23.94, p<.001$. All participants believed that spontaneously recalling the event was more likely to be due to spontaneous processes $(M=4.92, S D=$ 1.54) than deliberately recalling the event $(M=3.61, S D=1.79), t(200)=7.73, p<.001$.

\section{Self-Insight}

We examined the extent to which the recollection of the event would yield meaningful self-insight as a function of its valence and spontaneity in a 2(Rating Order: 
Insight First, Spontaneity First) x 2(Valence: Positive, Negative) x 2(Recollection: Spontaneous, Deliberate) mixed ANOVA with repeated measures on the last factor, which revealed two main effects. As we predicted, participants believed the recollection of the event would be more meaningful if it was recalled spontaneously $(M=3.50, S D=$ 1.11) than deliberately $(M=3.05, S D=1.09), F(1,197)=36.82, p<.001, \eta_{\mathrm{p}}{ }^{2}=.16$. While not central to our account, participants also believed that the recollection of a positive event $(M=3.54, S E=.09)$ was more meaningful than the recollection of a negative event $(M=3.02, S E=.09), F(1,197)=15.03, p<.001, \eta_{\mathrm{p}}{ }^{2}=.07$, perhaps demonstrating motivated reasoning (Kunda, 1990).

There was a marginally significant effect of rating order such that events were attributed greater meaning when self-insight was assessed before perceive spontaneity ( $M$ $=3.18, S D=1.15)$ than when perceived spontaneity was assessed before self-insight ( $M$ $=2.93, S D=1.01), F(197)=3.08, p=.08, \eta_{\mathrm{p}}{ }^{2}=.02$. There were no interactions between the event recalled and rating order, between the event recalled and valence, or between valence and rating order, all $F s<1$.

\section{Discussion}

Participants reported that recalling an event from their childhood would provide more meaningful self-insight if the event was recalled spontaneously than deliberately, regardless of whether the event they recalled was positive or negative. This was true whether they first considered the insight derived from the thought or the process that gave rise to the thought.

Considering the results of Studies 1 and 2, people appear to believe that spontaneous thoughts reveal more meaningful self-insight than do deliberate thoughts. 
We find evidence of this pattern for both categories of thought and specific thoughts (i.e., when the content of spontaneous and deliberate thoughts is held constant).

\section{STUDY 3: IMPRESSIONS}

In Study 3, we extended the test of our first hypothesis by examining the perceived meaning of thoughts as they are generated. Participants generated thoughts about four strangers through a spontaneous or deliberate process, and then rated extent to which those thoughts provided them with meaningful self-insight. Participants in the spontaneous thought condition reported the first word that came to mind when they saw a picture of each person, whereas in participants in the deliberate thought condition reported what they believed to be the most logical word to describe each person. We predicted that participants who generated their impressions spontaneously would believe their impressions provided them with more meaningful self-insight than would participants who generated their impressions deliberately, even when controlling for differences in the content of the impressions they generated.

\section{Participants}

One hundred and ninety-eight Americans (89 women; $M_{\text {age }}=32.09, S D=11.32$ ) completed a short survey on AMT for monetary compensation (see Appendix A).

\section{Procedure}

Participants saw photographs of four people (i.e., a young Black male lawyer, a teenage Asian male violinist, a young White female doctor, and an older White male judge) in a random order. After seeing each photograph, participants wrote down one word to describe their impression of the person. For each target, participants in the 
The (Perceived) Meaning of Spontaneous Thoughts - 18

spontaneous thought condition were asked, "What is the very first word that comes to mind when you think about how to describe the person below?” For each target, participants in the deliberate thought condition were asked, "Logically, what is a good way to describe the person below?” All participants then reported their impression and rated, “to what extent did your response reveal something meaningful about yourself to you?” on a 7-point scale with endpoints, Revealed nothing at all (1) and Definitely revealed something meaningful (7).

Results

\section{Self-Insight}

Ratings for the self-insight provided by the impressions of all four targets were averaged within participant $(\alpha=.82)$. Participants in the spontaneous thought condition reported that their responses revealed more meaningful self-insight $(M=3.58, S D=1.44)$ than did participants in the deliberate thought condition $(M=3.17, S D=1.42), t(196)=$ 2.04, $p=.04, r=.14$. In other words, participants believed the impressions they generated to reveal more meaningful information about themselves when those impressions were generated as the result of spontaneous thought processes than as a result of a deliberate thought process.

\section{Content}

We next examined potential differences in the content of thoughts that were generated in the spontaneous and deliberate conditions. Two coders (blind to the hypothesis and condition) rated if each impression generated by participants fell into one of four categories: race or gender, a job or social role, a trait, or other (average $\kappa=.79$ ). The coders also rated whether each word was positive $(+1)$, neutral $(0)$, or negative $(-1$; $\kappa$ 
$=.71)$. The coders also indicated whether the each response contained only one-word or multiple words $(\kappa=.98)$. For participants who gave a multiple word response for any target (9.59\%) a single "keyword" was coded, which was the first concept elicited. This keyword was used for all category coding.

Participants in the spontaneous thought condition were no more likely to mention the race/gender of the target, a job/social role, or a trait than participants in the deliberate thought condition, $t s<1$. Participants in the spontaneous thought condition were more likely to use a word that did not fall into these three categories (i.e., "other;" $M_{\text {spontaneous }}=$ $5.70 \%, S D=11.04)$ than did participants in the deliberate thought condition $\left(M_{\text {deliberate }}=\right.$ $2.89 \%, S D=6.17), t(196)=2.19, p=.03, r=.15$. Participants in the spontaneous thought condition also used less positive words to describe the targets $\left(M_{\text {spontaneous }}=+.25, S D=\right.$ .28) than did participants in the deliberate thought condition $\left(M_{\text {deliberate }}=+.42, S D=.30\right)$, $t(196)=4.08, p<.001, r=.28$.

These minor differences in content did not appear to underlie the greater meaning attributed to spontaneous thoughts than to deliberate thoughts. Including both valence and prevalence of "other" as covariates in an ANCOVA, with condition as the betweensubjects factor, did not reduce the greater self-insight attributed to spontaneous thoughts than to deliberate thoughts, $F(1,194)=4.74, p=.03, \eta_{p}{ }^{2}=.02$. Furthermore, including all of the content ratings as covariates did not decrease the greater self-insight attributed to spontaneous thoughts than to deliberate thoughts, $F(1,191)=7.18, p=.008, \eta_{p}{ }^{2}=.04$.

\section{Discussion}

Impressions of other people were believed to reveal more meaningful self-insight when generated spontaneously than deliberately. The greater self-insight gleaned from 
The (Perceived) Meaning of Spontaneous Thoughts - 20

spontaneous than deliberate impressions did not appear to be due to differences in their content. Controlling for differences in the content of the impressions generated, if anything, increased the greater meaning attributed to the spontaneous impressions than to the deliberate impressions.

The effect size for Study 3 was smaller those in Studies 1 and 2, which is likely to be due to the nature of the thought being considered. In the earlier studies participants considered the content of their thoughts and personal memories rather than fleeting impressions formed in an experiment. Yet, participants in Study 3 still reported gleaning greater self-insight from the brief impressions they formed of four complete strangers when those impressions were generated spontaneously rather than deliberately. Considered together with the results of Studies 1 and 2, the results suggest that the more spontaneous a thought appears to be, the more people believe it to reveal meaningful selfinsight (Study 1), even when controlling for the content and target of that thought (Studies 2 and 3).

\section{STUDIES 4 AND 5: SELF-INSIGHT AND IMPACT ON JUDGMENT}

Our last two studies extended the investigation by testing our first and second hypotheses: That spontaneous thoughts are believed to provide greater self-insight than similar deliberate thoughts, and that the greater meaning attributed to spontaneous thoughts results in those thoughts exerting a greater impact on judgment.

\section{STUDY 4: LICENTIOUS THOUGHTS AND ATTRACTION}


The (Perceived) Meaning of Spontaneous Thoughts - 21

Using a method suggested by Jacoby and Kelly (1992), participants were either directed to randomly or deliberately think of a person to whom they were attracted other than their present or most recent significant other. Compared to participants instructed to think deliberately, we predicted that participants who were instructed to think randomly would consider their thought to reveal more meaningful self-insight, and this attribution would lead them to infer that they were more attracted to the person who came to mind. Thus, we expected that the greater meaning that participants attributed to spontaneous thought would mediate its influence on their attraction to the person that they identified.

\section{Method}

\section{Participants}

Eighty-three adults in three experimental sessions conducted in Boston, MA (41 women; $M_{\text {age }}=23.0, \mathrm{SD}=7.2$ ) received $\$ 3$ for completing a questionnaire in a laboratory (see Appendix A).

\section{Procedure}

In a between-subjects design, participants in the random thought condition were instructed to "Let your mind wander, and try to randomly think of someone you know whom you are attracted to, other than your present or most recent significant other.” Participants in the deliberate thought condition were asked to "Think of someone you know whom you are attracted to, other than your present or most recent significant other.” As measures of the self-insight revealed by the thought, all participants then reported the insight a friend would gain about them if the friend knew which person they had identified and how meaningful it was that they thought of that person on 7-point scales with endpoints such as Not at all meaningful (1) and Very Meaningful (7). Finally, 
The (Perceived) Meaning of Spontaneous Thoughts - 22

participants rated how attracted they were to both that person and to their present or most recent significant other on 7-point scales with endpoints, Very Slightly Attracted (1) and Very Strongly Attracted (7).

\section{Results}

\section{Self-Insight}

As predicted, participants in the random thought condition believed that observers would gain greater insight if they knew the person they identified $(M=4.73, S D=1.37)$ than did participants in the deliberate thought condition $(M=3.97, S D=1.72), F(1,81)=$ 5.02, $p=.03, \eta_{p}{ }^{2}=.06$. Similarly, participants in the random thought condition believed their thought to have revealed more meaningful self-insight $(M=4.47, S D=1.97)$ than did participants in the deliberate thought condition $(M=3.63, S D=1.97), F(1,81)=$ $3.71, p=.058, \eta_{p}{ }^{2}=.04$. These measures were averaged as an index of self-insight in subsequent analyses, $r=.49 p<.001$.

\section{Preference}

Reported attraction to the target that participants generated and to their present or most recent significant other was analyzed in a 2 (thought: random, deliberate) X 2 (target: attractive other, significant other) mixed ANOVA with repeated measures on the last factor, which revealed a significant Thought $\mathrm{x}$ Target interaction, $F(1,81)=4.24, p=$ $.04, \eta_{p}{ }^{2}=.05$. As predicted, participants in the random thought condition reported being more attracted to the attractive other than did participants in the deliberate thought condition $\left(M_{\text {random }}=5.47, S D=1.46 ; M_{\text {deliberate }}=4.82, S D=1.43\right), t(81)=2.05, p=.04$. [Participants did not differ in their level of attraction to their present or most recent significant other $\left(M_{\text {random }}=4.33, S D=1.95 ; M_{\text {deliberate }}=4.89, S D=2.04\right), t(81)=1.28, p$ 
The (Perceived) Meaning of Spontaneous Thoughts - 23

$=.21$.] Offering further support for the potency of spontaneous thought, participants in the random thought condition actually reported being significantly more attracted to this other person than to their current significant other, $t(44)=2.76, p=.008$ (see Figure 2).

Insert Figure 2 About Here

\section{Analysis of Mediation}

The analyses above show that random thought was ascribed greater self-insight than similar deliberate thought, $\beta=.26, t(81)=2.41, p=.02$, and led participants to feel more attracted to the target they generated, $\beta=.22$, $t(81)=2.04, p=.04$. To test whether the greater self-insight attributed to random thoughts led participants to report being more attracted to the target, we conducted an analysis of mediation. When attraction to the target was regressed on kind of thought and the self-insight it was attributed, self-insight significantly predicted attraction to the target, $\beta=.47, t(81)=4.72, p<.001$, and mode of thought did not, $\beta=.10, t(81)=1.00, p=.32$. A mediation model (Hayes \& Scharkow, 2013), with maximum likelihood estimation and bias-corrected bootstrapping (20,000 resamples), revealed that the indirect effect of self-insight on attraction was significantly different from zero, $z=2.09, p=.04,95 \% \mathrm{CI}=.08$ to .77 . The reverse causal model (with attraction mediating the effect of spontaneity on self-insight) was not significant, $z$ $=0.87, p=.39,95 \% \mathrm{CI}=-.02$ to .10 .

\section{Discussion}

Participants who spontaneously generated a thought of a person to whom they were attracted believed that thought to reveal more self-insight and perceived their 
The (Perceived) Meaning of Spontaneous Thoughts - 24

attraction to be stronger than did participants who deliberately generated a thought of a person to whom they were attracted. Indeed, participants who spontaneously generated the thought of the person reported being more attracted to that person than to their significant other.

Our mediation analysis suggests that it was the greater self-insight attributed to the spontaneous thought that led that thought to exert a greater impact on their attitudestheir attraction to the target and their significant other. The results suggest that the content of spontaneous thought is believed to reveal more meaningful self-insight than the content of deliberate thought, and the greater meaning attributed to spontaneous thought leads it to exert a greater influence on attitudes.

\section{STUDY 5: MEMORIES RECALLED AND COMMITMENT}

The previous studies suggest that spontaneous thoughts are perceived to provide greater self-insight and more potently influence attitudes than similar deliberate thoughts. In Study 5, we sought to test whether spontaneous thoughts would also have a greater impact on behavioral intentions. Participants recalled a positive or negative experience related to their current or most recent relationship and then reported the extent to which the spontaneous and deliberate recollection of that memory would (a) provide them with meaningful self-insight and (b) increase or decrease the likelihood that they would end the relationship.

First, we predicted that participants would perceive the spontaneous recollection of positive and negative experiences to provide more self-insight than the deliberate recollection of the same memories. Second, we predicted that the spontaneous 
The (Perceived) Meaning of Spontaneous Thoughts - 25

recollection of both positive and negative memories would be perceived to have a greater influence on the propensity to end the relationship than their deliberate recollection. In other words, the spontaneous recollection of a positive memory should make participants less likely to end the relationship than the deliberate recollection of that positive memory, whereas the spontaneous recollection of a negative memory should make participants more likely to end the relationship than the deliberate recollection of that negative memory.

Method

\section{Participants}

Two hundred and one Americans (63 women; $M_{\text {age }}=30.74, S D=10.33$ ) completed a short survey on AMT for monetary compensation (see Appendix A). Procedure

Participants were randomly assigned to, “think of a positive [negative] experience with your current or most recent romantic partner now, to consider in the remainder of the study." They then rated the extent to which the experience recalled was positive or negative on a 7-point scale with endpoints, (1) Extremely Negative and (7) Extremely Positive.

Next, all participants rated both the spontaneous and deliberate recollection of that experience on three different dimensions, in a random order. As in Study 2, participants rated the extent to which recalling the experience would reveal something "meaningful (reveal something important about yourself)” if they recalled it spontaneously (i.e., “suddenly came to mind spontaneously”) and if they recalled it deliberately (i.e., "came to mind when you tried to remember it”) on two 5-point scales with endpoints, (1) Not at 
The (Perceived) Meaning of Spontaneous Thoughts - 26

all and (5) Extremely. As a manipulation check, participants rated, "If your memory of the experience with your partner came to mind when you tried to remember it [suddenly came to mind spontaneously], to what extent would you say that thought occurred spontaneously or as a result of a controlled thought process?” on two 7-point scales with endpoints, (1) Definitely Controlled and (7) Definitely Spontaneous. Finally, participants rated the influence of the spontaneous and deliberate recollection of the memory on their behavioral intentions by completing two items: “To what extent might recalling the experience affect your likelihood of ending the relationship, if it came to mind when you tried to remember it [suddenly came to mind spontaneously]” on 7-point scales with endpoints, (1) Definitely Decrease the Likelihood and (7) Definitely Increase the

\section{Likelihood.}

Results

\section{Manipulation Check}

Participants asked to recall a positive experience recalled a more positive experience $(M=6.12, S D=.95)$ than did participants asked to recall a negative experience $(M=2.93, S D=1.65), t(199)=17.28, p<.001$. Participants reported that spontaneously recalling the experience was more likely to be due to spontaneous processes $(M=4.92, S D=1.54)$ than deliberately recalling the experience $(M=3.34, S D$ $=1.75), t(200)=9.61, p<.001$.

\section{Self-Insight}

The extent to which the experience recalled was believed to reveal meaningful self-insight was examined in a 2(Process: Spontaneous, Deliberate) x 2(Valence: Positive, Negative) mixed ANOVA with repeated measures on the first factor. The 
spontaneous recollection of the experience was believed to reveal more meaningful selfinsight $(M=3.42, S D=1.04)$ than the deliberate recollection of that experience $(M=$ 3.04, $S D=1.08), F(1,199)=27.98, p<.001, \eta_{p}{ }^{2}=.12$.

While not central to our account, participants also believed that the recollection of a positive experience $(M=3.46, S E=.08)$ was more meaningful than the recollection of a negative experience $(M=2.93, S E=.10), F(1,199)=16.65, p<.001$. There was no interaction, $F<1$. Additionally, including question order in the model did not affect the significant main effects of process or valence, all $F \mathrm{~s}(1,189) \geq 12.19, p s \leq .001, \eta_{p}{ }^{2} \leq .06$.

\section{Behavioral Intentions}

The extent to which the experience recalled was believed to increase or decrease the likelihood of ending the relationship (relative to the scale midpoint of 4) was examined in a 2(Process: Spontaneous, Deliberate) x 2(Valence: Positive, Negative) mixed ANOVA with repeated measures on the first factor. The analysis revealed no main effect of process, but did reveal a main effect of valence. The recollection of a positive experience was believed have a greater influence on the likelihood of ending the relationship $(M=2.59, S D=.14)$ than the recollection of a negative experience $(M=$ 3.76, $S E=.17), F(1,199)=28.74, p<.001, \eta_{p}{ }^{2}=.13$. The was qualified by the predicted Process $x$ Valence interaction, $F(1,199)=17.27, p<.001, \eta_{p}{ }^{2}=.08$. [Including question order in the model did not affect this interaction, $F(1,189)=16.54, p<.001, \eta_{p}{ }^{2}=.08$.] 
The (Perceived) Meaning of Spontaneous Thoughts - 28

As illustrated by Figure 3, participants reported that spontaneously recalling a positive experience would make them less likely to end the relationship $(M=2.46, S D=$ 1.66) than deliberately recalling the same positive experience $(M=2.72, S D=1.66)$, $t(114)=2.64, p=.009$. In contrast, participants reported that spontaneously recalling a negative experience would make them more likely to end the relationship $(M=3.97, S D$ $=1.55)$ than deliberately recalling the same negative experience $(M=3.56, S D=1.64)$, $t(85)=3.12, p=.003$. Spontaneous thoughts - both positive and negative-thus exerted a greater influence on behavioral intentions than did the same deliberate thoughts. Indeed, ratings for the deliberate recollection of a negative experience were significantly lower than the scale midpoint, $t(85)=2.51, p=.01$, suggesting that deliberately recalling a negative memory led the content of that memory to have a countervailing influence on the likelihood of ending the relationship.

\section{GENERAL DISCUSSION}

Five studies offer support for our theoretical account that categories of thought, specific thoughts, and products of thoughts that are perceived to be spontaneous are believed to provide more meaningful self-insight, and consequently exert a greater influence on judgment. In Study 1, participants exhibited a belief that the more spontaneous a category of thought is perceived to be, the more self-insight it provides. In

Study 2, participants believed that the same thought would reveal more self-insight if generated spontaneously than deliberately, whether that thought was positive or negative. In Study 3, participants reported the impressions they generated to reveal more meaningful self-insight when those impressions were generated spontaneously than 
The (Perceived) Meaning of Spontaneous Thoughts - 29

deliberately, regardless of the particular content of the impression generated.

Spontaneously generated thoughts of a forbidden love were believed to reveal more meaningful self-insight than deliberately generated thoughts in Study 4. Consequently, spontaneously generated thoughts appeared to lead participants to feel greater attraction to the love interest they identified. Finally, participants believed the recollection of a positive or negative experience with their current romantic partner would reveal more self-insight and have a greater influence on their commitment to that relationship if it was recalled spontaneously than deliberately.

Across a variety of classes of thought and thought content including intuition, dreams, childhood memories, impression formation, sexual attraction, and relationship commitment, participants believed that thoughts perceived to have been spontaneously generated provided greater self-insight than similar deliberate thoughts. As a result, thoughts that appeared to have been generated spontaneously had a greater impact on judgments (i.e., attitudes and behavioral intentions) than did similar thoughts that appeared to have been generated deliberately.

It is possible that a portion of the greater self-insight and impact of spontaneous thought is due to differences in the typical content of spontaneous and deliberate thoughts rather than to the mere perception that a particular thought is spontaneous. However, controlling for thought content did not decrease the effect of thought spontaneity on perceived meaning (Study 3). Whatever differences in content exist between thoughts that are actually spontaneously and deliberately generated, the mere perception that a thought was generated spontaneously appeared sufficient to significantly increase the self-insight and importance it was attributed. Moreover, participants perceived the same 
The (Perceived) Meaning of Spontaneous Thoughts - 30

thought to be more meaningful if it was generated spontaneously than deliberately in Studies 2 and 5. Still, future research is needed to explore possible differences in the content of spontaneous and deliberate thoughts, and whether those possible differences in content influence the self-insight they provide. While Studies 2 and 5 relied on hypothetical scenarios to test the attribution of self-insight and importance to spontaneous and deliberate thoughts with the same content, future research would ideally explore this issue using a paradigm in which the actual and perceived spontaneity of the same thoughts are directly manipulated.

Which and When Are Spontaneous Thoughts Meaningful?

Although participants in the present research attributed more meaning to a wide range of spontaneous kinds of thought than deliberate thoughts with similar content, presumably, spontaneous thoughts may not always be believed to reveal more meaningful self-insight than deliberate thoughts. Intuition, a kind of thought perceived by participants to fall into the class of thoughts that are spontaneous (Study 1), is considered to be a better strategy than deliberation when making decisions that are based on subjective criteria such as choosing a spouse, or based on a few dimensions such as choosing a dessert. People consider intuition to be a worse strategy than deliberation, however, when making decisions that are based on objective criteria or that are complex, such as choosing which college to attend (Inbar, Cone, \& Gilovich, 2010). It is possible that when determining what complex set of alternatives would suit one best, such when deciding which college to attend, deliberation reveals an option that would be better for the self than intuition. Alternatively, people may ascribe greater self-insight to 
The (Perceived) Meaning of Spontaneous Thoughts - 31

spontaneous thoughts about which college to attend, but not rely to the same extent on those thoughts when making their decision.

We expect that the greater self-insight and importance attributed to spontaneous thoughts are likely to be moderated by the perceived self-relevance of the thought, the current context, and the motives and goals of the thinker. Spontaneous thoughts that arise while the thinker is judging some facet of the self are likely to be attributed greater selfinsight and importance than spontaneous thoughts that arise when making a judgment about another person or object, particularly when any self-insight provided by the thought is irrelevant to the judgment of the target. Spontaneous thoughts may be perceived to be more insightful in contexts that where subjective attributes such as opinions or preferences are more important than more objective attributes such as accuracy (Inbar et al., 2010). A spontaneous thought about a political candidate may be thought to reveal more self-insight in a conversation about which candidate one prefers than in a conversation about which candidate will win the election. Additionally, thoughts that the thinker perceives to be highly accessible because of an internal goal may be attributed to the importance of that goal rather than be believed to reveal meaningful self-insight (Loersch \& Payne, 2011). A spontaneous thought of a coworker may be perceived to reveal the importance of a project at work rather than insight into one's relationship with her.

Implicit in our account is the notion that participants attribute meaning to thoughts perceived to be spontaneous over and above the meaning these thoughts rightfully deserve. Varying the means by which one thinks of an attractive person other than one's current partner, for example, should not necessarily increase love for that person and 
The (Perceived) Meaning of Spontaneous Thoughts - 32

decrease love for one’s partner. More generally, much research on dual-process reasoning and judgment has documented how the products of spontaneous thought (e.g., intuitive judgments and decisions) are often inferior to the products of more deliberate thought (e.g., logic; Chaiken \& Trope, 1999; Evans, 2007; Frederick, 2005; Gilovich, Griffin, \& Kahneman, 2002; Morewedge \& Kahneman, 2010; Simmons \& Nelson, 2006).

At the same time, however, several streams of research suggest that thoughts that arise beyond people's control can reveal information that is inaccessible to the thinker. The associative reasoning that underlies much of spontaneous thought may actually produce as much or more insight into problems facing the thinker than more deliberative forms of reasoning (Dijksterhuis \& Meurs, 2006; Giblin, Morewedge, \& Norton, 2013; Nisbett \& Wilson, 1977; Schooler \& Melcher, 1995; Zhong, Dijksterhuis, \& Galinsky, 2008). Indeed, both unconscious thought and the consolidation of thought that occurs during sleep - truly a time in which thought is free from external influence- - have been shown to improve some decision-making and accelerate problem solving (e.g., Dijksterhuis, Bos, Nordgren, \& van Baaren, 2006; Stickgold \& Walker, 2004; Wagner et al., 2004; Wilson et al., 1993; Wilson \& Schooler, 1991).

Spontaneous thought can also reveal information unknown to-or deliberately masked by—the thinker. As adults are unwilling to publically reveal prejudiced thoughts and feelings (Norton, Sommers, Apfelbaum, Pura, \& Ariely, 2006), spontaneous associations and responses may allow for a better assessment of their explicit and implicit prejudices. Tests that tap into associative reasoning may allow the tester to circumvent rehearsed and strategic responses to questions about taboo and socially undesirable attitudes and behavior (Greenwald et al., 1998). More broadly, free-recall tasks can reveal 
The (Perceived) Meaning of Spontaneous Thoughts - 33

the strength of associations and the structure of memory (e.g., Roenker, Thompson, \& Brown, 1971; Segal \& Cofer, 1960; Storms, 1958; for a review, see Bargh \& Chartrand, 1999), which are likely to influence judgment and decision making (Hastie \& Park, 1986; Morewedge \& Kahneman, 2010; Tversky \& Kahneman, 1973).

To be sure, the domains in which scientific research has demonstrated the utility of spontaneous thought stand in stark contrast to the breadth of domains in which laypeople believe spontaneous thoughts to have real meaning. Hypnosis, for example, may be used to treat some disorders such as smoking cessation (Wadden \& Anderton, 1982). People's beliefs about the power of the thoughts revealed in hypnosis extend beyond the realm of the scientific, however, believing that the images that come to mind during hypnosis may offer evidence of past lives (Loftus, Garry, Brown, \& Rader, 1994; Spanos, Menary, Gabora, DuBreuil, \& Dewhirst, 1991). Similarly, while dreaming can serve to consolidate information in the service of problem-solving (Stickgold \& Walker, 2004; Wagner et al., 2004), lay beliefs about the insight revealed in dreams extends far beyond the intra-psychic information they might provide to the belief that the thoughts that occur in dreams can foretell the future (Morewedge \& Norton, 2009). The meaning attributed to such insight is not trivial—participants in these experiments reported they would be as likely to cancel or miss an airline flight if they dreamt of their plane crashing the night before they traveled as if there was an actual crash on the route they planned to take.

Lay beliefs about the meaningfulness of spontaneously generated thought may have consequences more serious than quirky beliefs about past achievements, canceled travel plans, and otherwise mildly superstitious behavior. The tendency to interpret and 
assign meaning to thoughts that intrude upon consciousness has been linked to psychological distress, autonomic arousal, auditory hallucinations among the mentally ill, and the propensity to self-harm among people with obsessive-compulsive tendencies (Magee \& Teachman, 2007; Morrison, 1994; Morrison, Haddock, \& Tarrier, 1995; Najmi et al., 2007).

\section{Conclusion}

We find evidence for a lay belief that spontaneous thoughts reveal particularly meaningful self-insight. Participants believed thoughts provided more meaningful selfinsight when they appeared to have been generated spontaneously than deliberately. This belief, in turn, led those thoughts to more potently impact their judgment. Spontaneous thoughts could be dismissed as meaningless because they are thoughts produced by uncontrolled mental processes to which the thinker lacks access. In contrast, the broad and pervasive belief in the special meaning and importance of the category of spontaneous thoughts appears to be due to the very lack of control over and access to their production, leading spontaneous thoughts to exert influence beyond what their content may warrant. 
The (Perceived) Meaning of Spontaneous Thoughts - 35

\section{REFERENCES}

Alter, A. L., Oppenheimer, D. M., Epley, N, \& Eyre, R. N. (2007). Overcoming intuition: Metacognitive difficulty activates analytic reasoning. Journal of Experimental Psychology: General, 136, 569-576.

Ariely, D. \& Norton, M.I. (2008). How actions create - not just reveal - preferences. Trends in Cognitive Sciences, 12, 13-16.

Banaji, M. R., \& Bhaskar, R. (2000). Implicit stereotypes and memory: The bounded rationality of social beliefs. In D. L. Schacter \& E. Scarry (Eds.), Memory, brain, and belief (pp.139-175). Cambridge, MA: Harvard University Press.

Bar-Anan, Y., Wilson, T. D., \& Hassin, R. (2010). Inaccurate self-knowledge formation as a result of automatic behavior. Journal of Experimental Social Psychology, 46, 884-894.

Bargh, J. A., \& Chartrand, T. L. (1999). The mind in the middle: A practical guide to priming and automaticity research. In H. T. Reis and C. M. Judd (Eds.) Handbook of research methods in social and personality psychology, pp. 253-285. New York: Cambridge University Press.

Bem, D. J. (1972) Self-perception theory. In L. Berkowitz (Ed.), Advances in Experimental Social psychology, Vol. 6, 1-62. New York: Academic Press.

Bem, D. J., \& McConnell, H. K. (1970). Testing the self-perception explanation of dissonance phenomena: On the salience of premanipulation attitudes. Journal of Personality and Social Psychology, 14, 23-31.

Bernstein, D. M., Laney, C., Morris, E. K., \& Loftus, E. F. (2005). False memories about food can lead to food avoidance. Social Cognition, 23(1), 11-34. 
Bless, H., \& Schwarz, N. (2010). Mental construal and the emergence of assimilation and contrast effects: The inclusion/exclusion model. Advances in Social Psychology, 42, 319-373.

Bowers, K., S., \& Farvolden, P. (1996). Revisiting a century-old Freudian slip—from suggestion disavowed to the truth repressed. Psychological Bulletin, 119, 355380.

Chaiken, S., \& Trope, Y. (Eds.). (1999). Dual-process theories in social psychology. New York: Guilford Press.

Cramer, P (1991). The Development of defense mechanisms: Theory, research, and assessment. New York: Springer-Verlag.

Critcher, C. R., Inbar, Y., Pizarro, D. A. (2013). How quick decisions illuminate moral character. Social Psychological and Personality Science, 4, 308-315.

Dijksterhuis, A., Bos, M. W., Nordgren, L. F., \& van Baaren, R. B. (2006). On making the right choice: The deliberation-without-attention effect. Science, 311, 10051007.

Dijksterhuis, A. \& Meurs, T. (2006). Where creativity resides: The generative power of unconscious thought. Consciousness and Cognition, 15, 135-146.

Dorus, E., Dorus, W., \& Rechtschaffen, A. (1971). The incidence of novelty in dreams. Annals of General Psychiatry, 25, 364-368.

Dutton, D. G. and Aron, A. P. (1974). Some evidence for heightened sexual attraction under conditions of high anxiety. Journal of Personality and Social Psychology, 30, 510-517. 
Epley, N., \& Gilovich, T. (2001). Putting adjustment back in the anchoring and adjustment heuristic: Divergent processing of self-generated and experimenterprovided anchors. Psychological Science, 12, 391-396.

Epley, N., \& Gilovich, T. (2006). The anchoring and adjustment heuristic: Why adjustments are insufficient. Psychological Science, 17, 311-318.

Erskine, J. A. K., \& Georgiou, G. J. (2010). Effects of thought suppression on eating behavior in restrained and non-restrained eaters. Appetite, 54, 499-503.

Erskine, J. A. K., Georgiou, G. J., \& Kvavilshvili, L. (2010). I suppress, therefore I smoke: Effects of thought suppression on smoking behavior. Psychological Science, 21, 1225-1230.

Evans, J. St. B. T. (2007). Hypothetical thinking: Dual-processes in reasoning and judgment. New York: Cambridge University Press.

Festinger, L., \& Carlsmith, J. M. (1959). Cognitive consequences of forced compliance. The Journal of Abnormal and Social Psychology, 58, 203-210.

Foster, C. A., Witcher, B. S., Campbell, W. K., \& Green, J. D. (1998). Arousal and attraction: Evidence for automatic and controlled processes. Journal of Personality and Social Psychology, 74, 86-101.

Frantz, C.M., Cuddy, A.J.C., Burnett, M., Ray, H., \& Hart, A. (2004). A threat in the computer: The race Implicit Association Test as a stereotype threat experience. Personality and Social Psychology Bulletin, 30, 1611-1624.

Frederick, S. (2005). Cognitive reflection and decision making. Journal of Economic Perspectives, 19, 24-42. 
Giblin, C. E., Morewedge, C. K., \& Norton, M. I. (2013). Unexpected benefits of deciding by mind wandering. Frontiers in Psychology, 4(598), doi: 10.3389/fpsyg.2013.00598.

Gilbert, D. T. (1991). How mental systems believe. American Psychologist, 46, 107-119.

Gilbert, D. T., Brown, R. P., Pinel, E. C., \& Wilson, T. D. (2000). The illusion of external agency. Journal of Personality and Social Psychology, 79, 690-700.

Gilovich, T., Griffin, D., \& Kahneman (2002). Heuristics \& biases: The psychology of intuitive judgment. New York: Cambridge University Press.

Goethals, G. R., \& Reckman, R. F. (1973). The perception of consistency in attitudes. Journal of Experimental Social Psychology, 9, 491-501.

Griffin, D. W., \& Ross, L. (1991). Subjective construal, social inference, and human misunderstanding. Advances in Experimental Social Psychology, 24, 319-359.

Green, J. P., \& Lynn, S. J. (2005). Hypnosis vs. relaxation: Accuracy and confidence in dating international news events. Applied Cognitive Psychology, 19, 679-691.

Greenwald, A. G., McGhee, D. E., Schwartz, J. L. K. (1998). Measuring individual differences in implicit cognition: The implicit association test. Journal of Personality and Social Psychology, 74, 1464-1480.

Hastie, R., \& Park, B. (1986). The relationship between memory and judgment depends on whether the judgment task is memory-based or on-line. Psychological Review, 93, 258-268.

Hayes, A. F., \& Scharkow, M. (2013). The relative trustworthiness of inferential effects of the indirect effect in statistical mediation analyses: Does method really matter? Psychological Science, 24, 1918-1927. 
Holmes, D. (1968). Dimensions of projection. Psychological Bulletin, 69, 248-268.

Inbar, Y., Cone, J., \& Gilovich, T. (2010). People’s intuitions about intuitive insight and intuitive choice. Journal of Personality and Social Psychology, 99, 232-247.

Jacoby, L. L., \& Kelley, C. M. (1992). A process-dissociation framework for investigating unconscious influences: Freudian slips, projective test, subliminal perception, and signal detection theory. Current Directions in Psychological Science, 1, 174-179.

Kahneman, D. \& Frederick, S. (2002). Representativeness revisited: Attribute substitution in intuitive judgment. In T. Gilovich, D. Griffin, and D. Kahneman [eds]. Heuristics \& biases: The psychology of intuitive judgment (pp. 49-81). New York: Cambridge University Press.

Kruger, J., Wirtz, D., \& Miller, D. T. (2005). Counterfactual thinking and the first instinct fallacy. Journal of Personality and Social Psychology, 88, 725-735.

Kupor, D.M., Tormala, Z.L., Norton, M.I., \& Rucker, D.D. (in press). Thought calibration: How thinking just the right amount increases one’s influence and appeal. Social Psychological and Personality Science.

Loersch, C., \& Payne, K. (2011). The situated inference model: An integrative account of the effects of primes on perception, behavior, and motivation. Perspectives on Psychological Science, 6, 234-252.

Loftus, E. F. (1993). The reality of repressed memories. American Psychologist, 48, 518537. 
Loftus, E.F., Garry, M., Brown, S.W., \& Rader, M. (1994). Near-natal memories, pastlife memories, and other memory myths. American Journal of Clinical Hypnosis, 36, 176-179.

Magee, J. C., \& Teachman, B. A. (2007). Why did the white bear return? Obsessivecompulsive symptoms and attributions for unsuccessful thought suppression. Behavior Research and Therapy, 45, 2884-2898.

Mednick, S.A., \& Mednick, M.T. (1967). Examiner’s manual: Remote associates test. Boston: Houghton Mifflin.

Miller, G. A. (1962). Psychology: The science of mental life. New York: Harper \& Row. Morewedge, C. K., \& Kahneman, D. (2010). Associative processes in intuitive judgment. Trends in Cognitive Sciences, 14, 435-440.

Morewedge, C. K., \& Norton, M. I. (2009). When dreaming is believing: The (motivated) interpretation of dreams. Journal of Personality and Social Psychology, 92, 249264.

Morrison, A. P. (1994). Cognitive behaviour therapy for auditory hallucinations without concurrent medication: A single case. Behavioural \& Cognitive Psychotherapy, 22, 259-264.

Morrison, A. P., Haddock, G., \& Tarrier, N. (1995). Intrusive thoughts and auditory hallucinations: A cognitive approach. Behavioural \& Cognitive Psychotherapy, 23, 265-280.

Murray, H. (1951). Uses of the Thematic Apperception Test. American Journal of Orthopsychiatry, 21, 577-581. 
Najmi, S., Wegner, D. M., \& Nock, M. K. (2007). Thought suppression and self-injurious thoughts and behaviors. Behaviour Research and Therapy, 45, 1957-1965.

Nikles, C. D., Brecht, D. L., Klinger, E., \& Bursell, A. L., (1998). The effects of currentconcern- and nonconcern-related waking suggestions on nocturnal dream content. Journal of Personality and Social Psychology, 75, 242-255.

Nisbett, R. E., \& Wilson, T. D. (1977). Telling more than we can know: Verbal reports on mental processes. Psychological Review, 84, 231-259.

Norman, D. A. (1981). Categorization of action slips. Psychological Review, 88, 1-15.

Norton, M. I., Sommers, S. R., Apfelbaum, E. P., Pura, N., \& Ariely, D. (2006). Color blindness and interracial interaction: Playing the political correctness game." Psychological Science, 17, 949-953.

Poole, D. A., Lindsay, S. J., Memon, A., \& Bull, R. (1995). Psychotherapists’ opinions, practices, and experiences with recovered memories of incestuous abuse. Journal of Consulting and Clinical Psychology, 68, 426-437.

Pronin, E., Gilovich, T., \& Ross, L. (2004). Objectivity in the eye of the beholder: Divergent perceptions of bias in self versus others. Psychological Review, 111, 781-799.

Roenker, D. I., Thompson, C. P., \& Brown, S. C. (1971). Comparison of measures for the estimation of clustering in free recall. Psychological Bulletin, 1, 45-48.

Rosenthal, R., \& Rosnow, R. L. (1991). Essentials of behavioral research: Methods and data analysis (2 ${ }^{\text {nd }}$ Edition). Boston, MA: McGraw-Hill.

Ross, L., \& Nisbett, R. E. (1991). The person and the situation. New York: McGrawHill. 
The (Perceived) Meaning of Spontaneous Thoughts - 42

Schooler, J. W., Bendiksen, M., \& Ambadar, Z. (1997). Taking the middle line: Can we accommodate both fabricated and recovered memories of sexual abuse? Recovered memories and false memories. In M. Conway (ed.), Recovered memories and false memories. Debates in psychology (pp. 251-292). New York: Oxford University Press.

Schooler, J. W., \& Melcher, J. (1995). The ineffability of insight. In S. M. Smith, T. B. Ward, and R. A. Finke (eds.), The creative cognition approach (pp. 97-133). Cambridge, MA: MIT Press.

Schwarz, N., \& Bless, H. (1992). Constructing reality and its alternatives: An inclusion/exclusion model of assimilation and contrast effects in social judgment. In L. L. Martin \&A. Tesser (Eds.), The construction of social judgment (pp. 249275). Hillsdale, NJ: Erlbaum.

Schwarz, N., Bless, H., Strack, F., Klumpp, G., Rittenauer-Schatka, H., \& Simons, A. (1991). Ease of retrieval as information: Another look at the availability heuristic. Journal of Personality and Social Psychology, 61, 195-202.

Schwarz, N. \& Clore, G. L. (1983). Mood, misattribution, and judgments of well-being: Informative and directive functions of affective states. Journal of Personality and Social Psychology, 45, 513-523.

Segal, S. J., \& Cofer, C. N. (1960). The effect of recency and recall on word association. American Psychologist, 15, 451.

Simmons, J. P., \& Nelson, L. D. (2006). Intuitive confidence: Choosing between intuitive and nonintuitive alternatives. Journal of Experimental Psychology: General, 135, 409-428. 
Shiv, B., \& Fedorikhin, A. (1999). When heart and mind are in conflict: The interplay of affect and cognition in consumer decision making. Journal of Consumer Research, 26, 278-292.

Smallwood, J. M. \& Schooler, J. W. (2006). The restless mind. Psychological Bulletin, 132, 946-958.

Spanos, N. P., Menary, E., Gabora, M. J., DuBreuil, S. C., \& Dewhirst, B. (1991). Secondary identity enactments during hypnotic past-life regression: A sociocognitive perspective. Journal of Personality and Social Psychology, 61, 308-320.

Stickgold, R., \& Walker, M. (2004). To sleep, perchance to gain creative insight? Trends in Cognitive Sciences, 8, 191-192.

Storms, L. H. (1958). Apparent backwards association: A situational effect. Journal of Experimental Psychology, 55, 390-395.

Teasdale, J. D., Dritschel, B. H., Taylor, M. J., Proctor, L., Lloyd, C. A., Nimmo-Smith, I., \& Baddeley, A. D. (1995). Stimulus independent thought depends on central executive resources. Memory and Cognition, 23, 551-559.

Tversky, A., \& Kahneman, D. (1973). Availability: A heuristic for judgment frequency and probability. Cognitive Psychology, 5, 207-232.

Wagner, U., Gais, S., Haider, H., Verleger, R., \& Born, J. (2004). Sleep inspires insight. Nature, 427, 352-355.

Wegener, D. T., \& Petty, R. E. (1995). Flexible correction processes in social judgment: The role of naive theories in corrections for perceived bias. Journal of Personality and Social Psychology, 68, 36-51. 
Wegner, D. M. (2009). How to think, say, or do precisely the worst thing for any occasion. Science, 325, 48-51.

Wegner, D. M., Shortt, J. W., Blake, A. W., \& Page, M. S. (1990). The suppression of exciting thoughts. Journal of Personality and Social Psychology, 58, 409-418.

Wegner, D. M., \& Smart, L. (1997). Deep cognitive activation: A new approach to the unconscious. Journal of Consulting and Clinical Psychology, 65, 984-995.

Wegner, D. M., Wenzlaff, R. M., \& Kozak, M. (2004). Dream rebound: The return of suppressed thoughts in dreams. Psychological Science, 15, 232-236.

Westen, D. (1991). Clinical assessment of object relations using the TAT. Journal of Personality Assessment, 56, 56 - 74.

Wadden, T. A., \& Anderton, C. H. (1982). The clinical use of hypnosis. Psychological Bulletin, 91, 215-243.

Wilson, T. D. (2002). Strangers to ourselves: Discovering the adaptive unconscious. Cambridge, MA: Harvard University Press.

Wilson, T. D., \& Brekke, N. (1994). Mental contamination and mental correction: Unwanted influences on judgments and evaluations. Psychological Bulletin, 116, $117-142$.

Wilson, T. D., Lisle, D. J., Schooler, J. W., Hodges, S. D., Klaaren, K. J., \& LaFleur, S. J. (1993). Introspecting about reasons can reduce post-choice satisfaction. Personality and Social Psychology Bulletin, 19, 331-339.

Wilson, T.D. \& Schooler, J.W. (1991). Thinking too much: Introspection can reduce the quality of preferences and decisions. Journal of Personality and Social Psychology, 60, 181-192. 
The (Perceived) Meaning of Spontaneous Thoughts - 45

Winkielman, P., \& Schwarz, N. (2001). How pleasant was your childhood? Beliefs about memory shape inferences from experienced difficulty of recall. Psychological Science, 12, 176-179.

Zhong, C. B., Dijksterhuis, A., \& Galinsky, A. D. (2008). The merits of unconscious thought in creativity. Psychological Science, 19, 912-918. 


\begin{abstract}
AUTHOR NOTE
Carey K. Morewedge and Colleen E. Giblin, Tepper School of Business, Carnegie Mellon University; Michael I. Norton, Department of Marketing, Harvard Business

School.
\end{abstract}

Please address correspondence concerning this article to Carey K. Morewedge, Tepper School of Business, Carnegie Mellon University, 5000 Forbes Ave., Pittsburgh, PA, 15224, or by email to morewedge@cmu.edu. 
The (Perceived) Meaning of Spontaneous Thoughts - 47

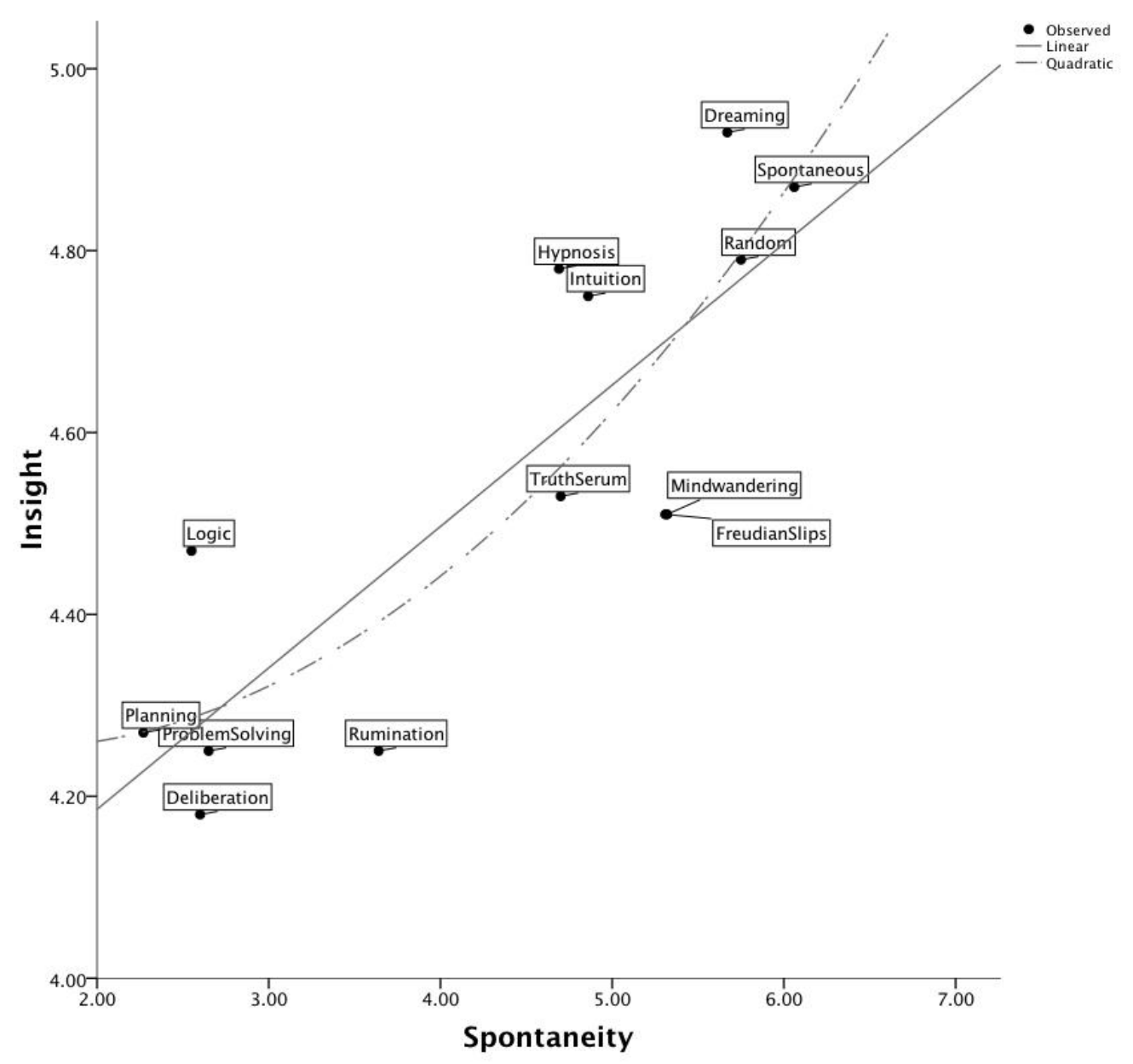

Figure 1. The more spontaneous a form of thought, the more insight it was believed to reveal about the mind of the thinker in Study 1. 


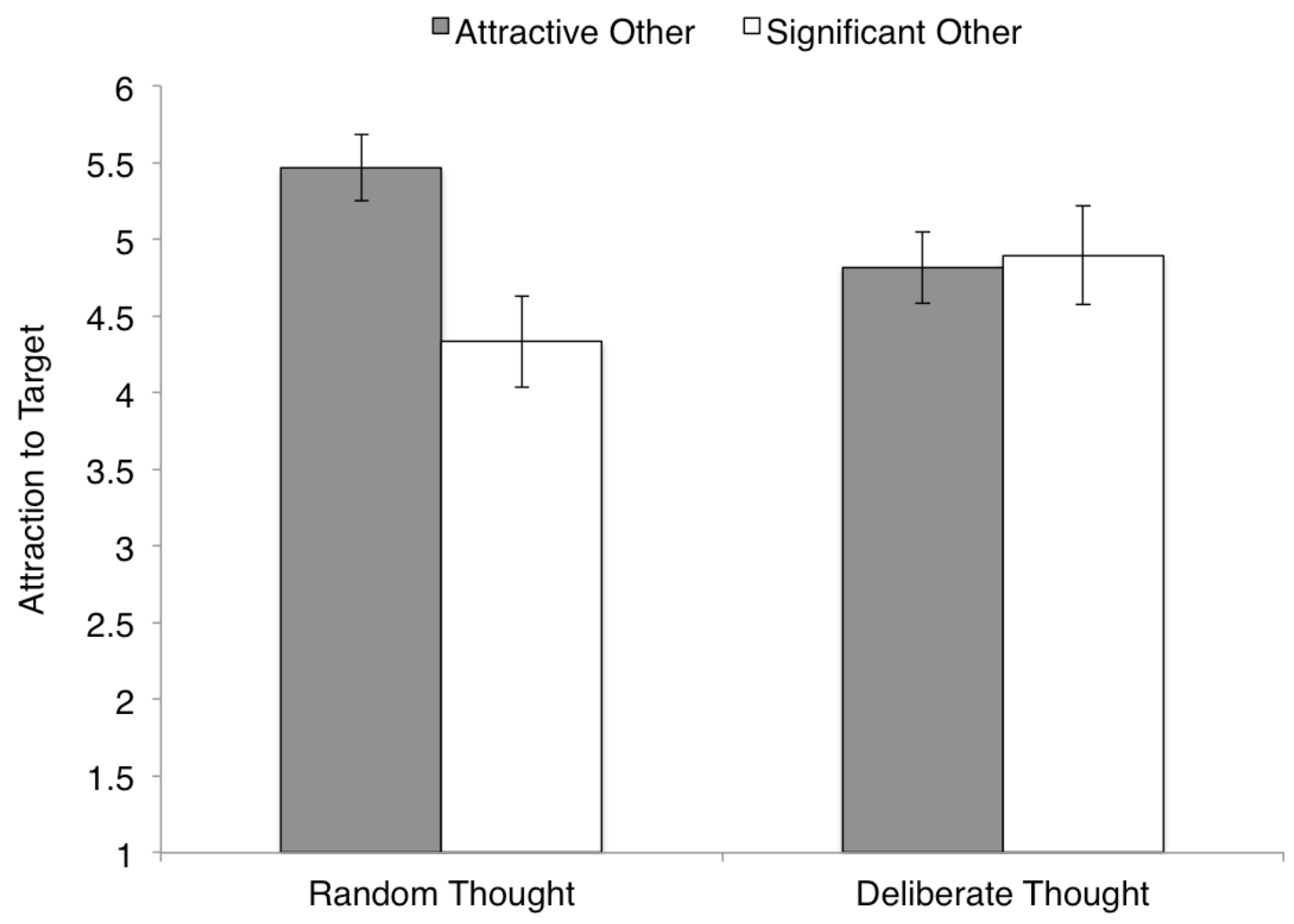

Figure 2. Participants who identified an attractive other with spontaneous thought were more attracted to that other than participants who identified the other with deliberate thought in Study 4. Only spontaneous thinkers were more attracted to that person than their present or most recent significant other. Bars reflect +/1 SEM. 


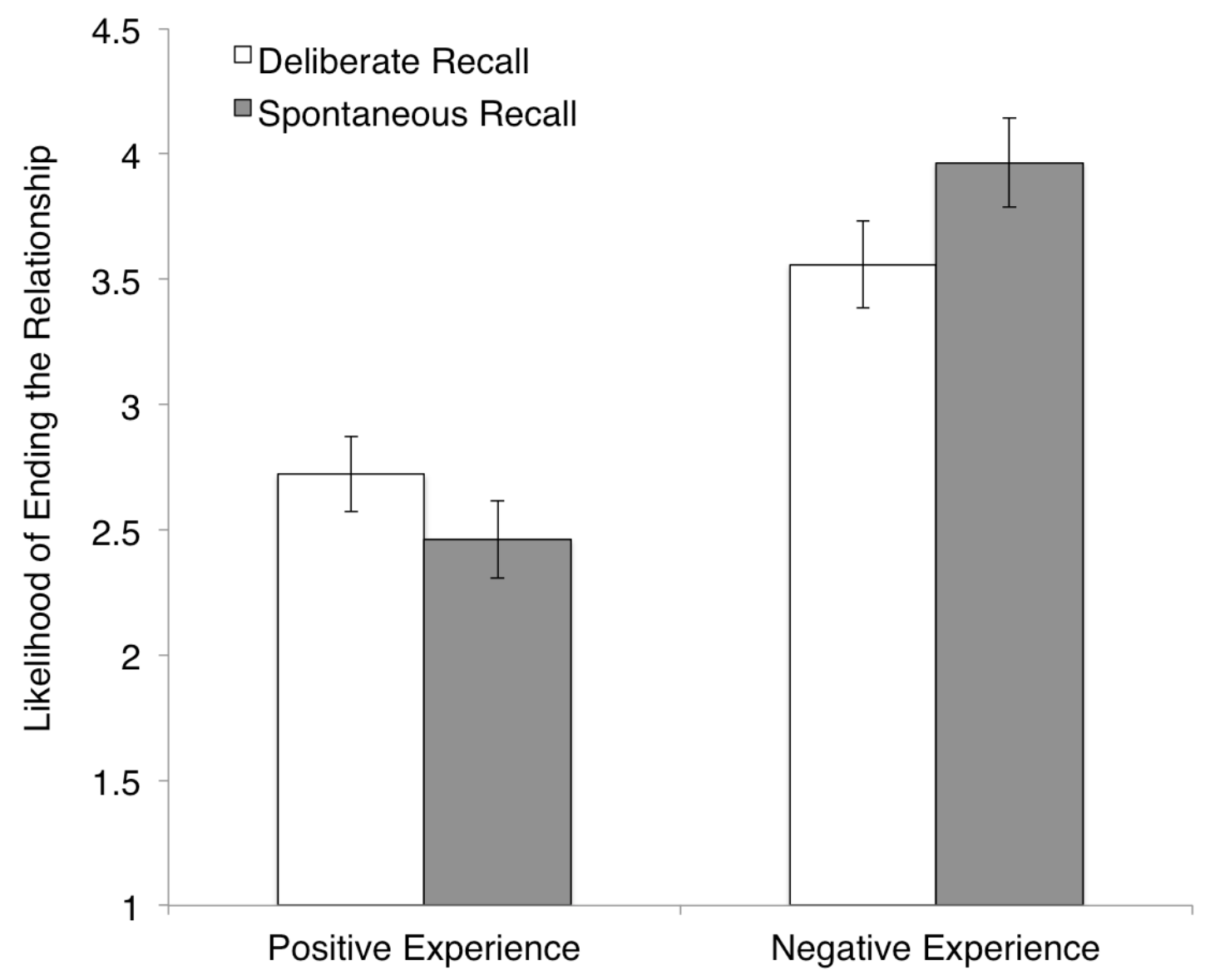

Figure 3. Spontaneously recalled positive and negative experiences had a greater influence on the likelihood of ending a relationship than did the same deliberately recalled experience in Study 5. Scale midpoint is 4. Bars reflect \pm 1 SEM. 
The (Perceived) Meaning of Spontaneous Thoughts - 50

\section{APPENDIX A}

Study 1. Two hundred hits were requested from Amazon Mechanical Turk to complete a survey on Qualtrics. All participants had an AMT approval rating equal to or higher than 95\%. One hundred and ninety-nine participants completed the survey (incomplete surveys were not saved). Of the 199 participants, 17 failed the attention filter described in the procedure section of the study (no other experiments included an attention filter; the studies are not reported in chronological order).

Study 2. Two hundred hits were requested from Amazon Mechanical Turk to complete a survey on Qualtrics. All participants had an AMT approval rating equal to or higher than 95\% and reside in the United States of America. Two hundred and one participants completed the survey (incomplete surveys were not saved); the larger than requested sample is likely due a delay between the completion of the $200^{\text {th }}$ survey and the entry of its the completion code in AMT (which would close the survey to new participants).

Study 3. Two hundred hits were requested from Amazon Mechanical Turk to complete a survey on Qualtrics. All participants had an AMT approval rating equal to or higher than 95\%. One hundred and ninety-eight participants completed the survey (incomplete surveys were not saved).

Study 4. Residents of Boston, MA were recruited in advance to complete a series of unrelated experiments in three two-hour experimental sessions of up to 36 participants at a time. Each participant completed the series of unrelated experiments on a separate 
computer in a private cubicle in a computer laboratory. Of the session participants, 83 completed this experiment.

Study 5. Two hundred hits were requested from Amazon Mechanical Turk to complete a survey on Qualtrics. All participants had an AMT approval rating equal to or higher than 95\% and reside in the United States of America. Two hundred and one participants completed the survey (incomplete surveys were not saved); the larger than requested sample is likely due a delay between the completion of the $200^{\text {th }}$ survey and the entry of its the completion code in AMT (which would close the survey to new participants). 